\title{
Enterococcal Infections and Antimicrobial Resistance in a Tertiary Care Hospital, Eastern India
}

\author{
Llalli S Sahu', Muktikesh Dash², Bimoch P Paty ${ }^{3}$, \\ Gopal K Purohit $^{4}$, Nirupama Chayani ${ }^{5}$ \\ ${ }^{1}$ Microbiology Department, S.C.B Medical College and Hospital, Utkal University, \\ Cuttack, Odisha, India. \\ ${ }^{2}$ Microbiology Department, S.C.B Medical College and Hospital, Utkal University, \\ Cuttack, Odisha, India. \\ ${ }^{3}$ Microbiology Department, S.C.B Medical College and Hospital, Utkal University, \\ Cuttack, Odisha, India. \\ ${ }^{4}$ Biotechnology School, KIIT University, Bhubaneswar, Odisha, India. \\ ${ }^{5}$ Microbiology Department, S.C.B Medical College and Hospital, Utkal University, \\ Cuttack, Odisha, India.
}

Corresponding Author Muktikesh Dash

Mobile:

+919861046640

E mail:

mukti_mic@yahoo.co.in

Key words:

Enterococci, E.

faecalis, E. faecium,

$V R E$, vanA gene
Background and study aim: During last two decades, there has been a world-wide trend in increasing occurrence of enterococcal infections in the hospitals. The aim of present study was to determine the spectrum of enterococcal infections, species prevalence, antimicrobial resistance and characteristics of vancomycin resistant enterococci (VRE) in a tertiary care hospital, Eastern India.

Patients and methods: Between January 2013 and July 2014, 152 Enterococcus species were obtained from clinical samples. Enterococci were identified using standard biochemical tests. Antimicrobial susceptibility was tested by Kirby-Bauer disk diffusion according to Clinical \& Laboratory Standards Institute (CLSI) guidelines.VRE agar base was used to screen VRE isolates. Minimum inhibitory concentration (MIC) values of VRE isolates were determined using Epsilometer-test. VRE isolates were also examined by PCR to detect vanA gene.

Results: From 1602 clinical samples, 961 $(60 \%)$ were culture positive and 152

\section{INTRODUCTION}

Gram-positive enterococci are normal commensals of the gastrointestinal tract, oral cavity, genitourinary tract and skin especially perineal area in both humans and animals [1]. Enterococci are traditionally regarded as low grade pathogens but have emerged as an important cause of nosocomial infections in recent years. Although 19 species within the genus have been recognized, E. faecalis is the most predominantly
$(15.8 \%)$ enterococcal isolates were obtained. Most common species isolated was $E$. faecalis $(63.8 \%)$ followed by E. faecium $(35.5 \%)$. Majority of enterococcal infections were detected from ICUs and surgical wards and clinically presented as UTIs. Disk diffusion method showed $67.1 \%$ were resistant to penicillin, $61.2 \%$ ampicillin, $58.5 \%$ ciprofloxacin, $46.7 \%$ high-level gentamicin, $42.8 \%$ high-level streptomycin, $7.9 \%$ teicoplanin and none to linezolid. Twenty (13.2\%) enterococcal isolates were vancomycin resistant in VRE screen and disk diffusion method. Epsilometertest of VRE isolates showed $8(40 \%)$ isolates were resistant and $9(45 \%)$ were intermediately resistant. From 20 VRE isolates, six showed VanA and two VanB phenotypes and all six VanA phenotypes had vanA gene cluster.

Conclusion: More accurate and reliable MIC determination tests should be performed in all suspected VRE isolates. Confirmatory PCR is required for identifying resistant gene cluster.

isolated pathogen, followed by $E$. faecium [2]. The most frequent infections caused by enterococci are urinary tract infections, followed by intra-abdominal and intra-pelvic abscesses, post operative wound infections and blood stream infections $[3,4]$. The rise in prevalence of enterococcal infections in humans is influenced by the ability of enterococci to escape the action of most commonly used antibiotics. 
Acquired high-level aminoglycoside resistance (HLAR), B-lactamases production, glycopeptide resistance including vancomycin resistance enterococci (VRE) have emerged, thus posing therapeutic challenge to the health care professionals [5]. In recent years, VRE are the main sources of infections in humans and carry the transferable vancomycin resistance markers [6]. Despite the increasing reports of VRE in different countries, there is little known about its prevalence and characteristics in Eastern India. Therefore, this study was undertaken to identify the different species of enterococci isolated from clinical specimens, their antimicrobial resistance patterns, prevalence and characteristics of VRE in a tertiary care hospital, Eastern India.

\section{PATIENTS AND METHODS}

\section{Study design and data collection:}

A prospective was conducted from July 2013 to June 2014 in the department of clinical microbiology at a tertiary care hospital, Odisha state, Eastern India. A total of 1602 clinical specimens i.e., urine, pus/wound swabs, blood and body fluids were collected from patients and transferred to the laboratory without delay for further processing. Specimens such as throat swabs, sputum and faeces were excluded as enterococci are usually remain as commensals. A detailed evaluation of patient's age, sex, address, associated co-morbidities, admission to the hospital, duration of stay in the hospital and antibiotic treatment history was carried out. An infection is considered as nosocomial if all the elements of a site specific infection criterion of Center of Disease Control and Prevention (CDC) were first present together on or after the $3{ }^{\text {rd }}$ hospital day (day of hospital admission is day 1) [7].

\section{Sample processing and identification of Enterococcus species:}

In the laboratory, all the collected samples were cultured aerobically on solid media i.e., blood agar and MacConkey agar. Blood specimen was cultured in trypticase soy broth (TSB) and subcultured on blood agar, chocolate agar and MacConkey agar. All cultured plates were incubated at $37^{\circ} \mathrm{C}$ for 48 hours and examined for growth. Identification of genus Enterococcus was done by using colony morphology, Gram stain, catalase test, bile esculin agar hydrolysis test, growth in $6.5 \% \mathrm{NaCl}$ (salt tolerance test), growth at $10^{\circ} \mathrm{C}$ and $45^{\circ} \mathrm{C}$ (heat tolerance test) [8]. Speciation was done by detecting fermentation of arabinose, mannitol, raffinose and sorbitol as well as motility and pigment production, if any [9].

Antimicrobial susceptibility testing and phenotypic detection of vancomycin resistance enterococci (VRE):

All enterococcal isolates were subjected to antimicrobial susceptibility testing by the standard Kirby-Bauer disk diffusion method (KBDDM) [10]. The following standard antibiotic disks were placed on Mueller-Hinton agar plate: penicillin (10U/disk), ampicillin $(10 \mu \mathrm{g})$, ciprofloxacin $(5 \mu \mathrm{g})$, high-level gentamicin $(120 \mu \mathrm{g})$, high-level streptomycin $(300 \mu \mathrm{g})$, vancomycin $(30 \mu \mathrm{g})$, teicoplanin $(30 \mu \mathrm{g})$, and linezolid $(30 \mu \mathrm{g})$. Zone diameter was measured and interpreted according to standards of the clinical and laboratory standards institute (CLSI) [11]. Quality control strain E. faecalis (ATCC 51299) were used to ensure the potency of each antimicrobial agent used.

Vancomycin agar screen test was performed by using VRE agar base supplemented with vancomycin and meropenem. Cultural characteristics of luxuriant growth along with blackening of the medium were seen after an incubation of $35^{\circ} \mathrm{C}$ for 24 to 48 hours in VRE isolates. Vancomycin sensitive strain E. faecalis (ATCC 29212) was used as negative control and vancomycin resistant strain E. faecalis (ATCC 51299) was used as positive control [11].

Minimum inhibitory concentration (MIC) of VRE isolates were determined by Epsilometer test (E-test) method. The MIC determination paper strip was coated with vancomycin in a concentration gradient manner capable of showing MICs in the range of 0.016 to $256 \mu \mathrm{g} / \mathrm{ml}$, when testing against Enterococcus species. MIC values of $\leq 4 \mu \mathrm{g} / \mathrm{ml}, 8-16 \mu \mathrm{g} / \mathrm{ml}$, and $\geq 32 \mu \mathrm{g} / \mathrm{ml}$ were considered as sensitive, intermediate resistant and resistant isolates respectively. Similarly, the MIC values of VRE isolates were detected for teicoplanin and linezolid respectively.

All culture media, biochemical reagents, antibiotic discs, vancomycin agar screen test, MIC test strips and standard reference strains used in the study were purchased from Hi Media Laboratories Pvt. Ltd., Mumbai, India.

\section{Genotypic detection of Enterococci and VRE isolates \\ 16S rRNA genes expression for enterococcal isolates: \\ 16S rRNA sequence was amplified from genomic DNA obtained for PCR with the upstream primer:}


27F Primer-5'-GAGTTTGATCMTGGCTCAG-3' and the downstream primer: 1492R Primer-5'GGYTACCTTGTTACGACTT-3', which generated a DNA fragment of approximately $1500 \mathrm{bp}$. Both of forward and reverse primers were ordered from IDT genomics, Japan.

\section{PCR amplification of 16S rRNA genes:}

Total 31DNA isolate mixtures were used in 16S rRNA amplification. PCR was performed in a reaction volume of $25 \mu \mathrm{L}$ containing $1 \mathrm{X}$ Taq polymerase buffer with $1.5 \mathrm{mmol} / \mathrm{L}-1$ of $\mathrm{MgCl} 2$ (New England Biolab, USA), $100 \mu \mathrm{L} / \mathrm{mol} / \mathrm{L}-1$ of each dNTP (3B black bio, JAPAN), 0.5 pmol of forward and reverse primers, 50-100 ng of genomic DNA and1.0 U of Taq DNA polymerase (New England biolab, USA). PCR amplifications were performed in a thermal cycler (Biorad, USA). Primers specific to bacterial 16SrRNA were used for PCR amplification. The thermal conditions for 16SrRNA primer pair were $\left[94^{\circ} \mathrm{C}\right.$ for predenaturation, $5 \mathrm{~min}$ (one cycle); $94^{\circ} \mathrm{C}$ for denaturation, $1 \mathrm{~min}$, annealing $55^{\circ} \mathrm{C}, 1 \mathrm{~min}$, extension $72^{\circ} \mathrm{C}, 2$ min (30cycles); final extension $72^{\circ} \mathrm{C}, 10 \mathrm{~min}$ (one cycle)]. The amplified products were resolved in $1.5 \%$ agarose gel, stained with ethidium bromide $(10 \mathrm{mg} / \mathrm{ml})$ and photographed under UVP version gel documentation system. Negative and positive controls were included in PCR reactions.

Reproducibility of PCR reactions was checked by performing duplicate reactions for each template DNA isolated. DNA templates used in the study were able to give reproducible PCR amplification results in duplicated experiment. All amplified products were separated by electrophoresis in $1.5 \%$ agarose gels with $10 \mathrm{mg} / \mathrm{mL}-1$ of ethidium bromide at $50 \mathrm{~V}$ constant voltages for $2 \mathrm{~h}$. The gels were scanned in Gel documentation system (UVP Laboratories, USA) [Figure 1].

\section{Primer designing for vancomycin resistance gene:}

One candidate $\operatorname{van} A$ vancomycin resistance gene cluster was evaluated in this study. Resistance genes sequences were collected from the previously submitted NCBI data base (http://www.ncbi.nlm. nih.gov/). All the collected sequences were multiple aligned for online EMBL clastalW data base (http://www.ebi.ac.uk/Tools/msa/clustalw2/). Primers were designed using Primer3 online software (http://primer3.ut.ee/). Forward primer: 5'-GGATAGCTACTCCCGCCTTT-3' and reverse primer: 5'-CCGTTTCCTGTATCCGTCCT-3' were used which generated an amplicon size of approximately $350 \mathrm{bp}$ for vanA gene cluster. The specificity of the primer sets were confirmed by the presence of a single band of appropriate size obtained after PCR amplification. The amplicons were sequenced and submitted to gene bank data base by BLASTN analysis against the vancomycin resistance bacterial genome; the uniqueness of the primers was examined.

\section{PCR amplification for vancomycin resistance gene:}

PCR was performed in a total volume of $25 \mu \mathrm{l}$ containing $10 \mathrm{pmol}$ each of forward and reverse primers, $2.5 \mathrm{mM}$ of $\mathrm{MgCl} 2,200 \mu \mathrm{M}$ each of the four deoxyribonucleotide triphosphates (dNTPs), $0.5 \mathrm{U}$ of Taq DNA polymerase, 1x concentration of PCR buffer (Invitrogen, Life Technologies, Brazil) and 50 to $100 \mathrm{ng}$ of isolated bacterial genomic DNA. The template was denatured by heating at pre-denaturation of $95^{\circ} \mathrm{C}$ for $5 \mathrm{~min}$. This was followed by 39 cycles of denaturation $30 \mathrm{sec}$ at $95^{\circ} \mathrm{C}, 45 \mathrm{sec}$ annealing and $1 \mathrm{~min}$ elongation at $72^{\circ} \mathrm{C}$, with a final extension of 7 min at $72^{\circ} \mathrm{C}$. The Bio-Rad PCR system was used for PCR amplification. The amplicons were resolved in $1.5 \%$ agarose gel using $0.5 \mathrm{x}$ trisacetate-EDTA (TAE) buffer.

\section{RESULTS}

\section{Enterococcal isolates:}

Out of 1602 clinical specimens, 961 (60\%) were culture positive and $152(15.8 \%)$ non-repeated enterococcal isolates were obtained. E. faecalis was the commonest species $97(63.8 \%)$ isolated, followed by $E$. faecium $54(35.5 \%)$ and $E$. casseliflavus $1(0.7 \%)$. Maximum number of Enterococcus species were detected from urine $89(58.6 \%)$, followed by wound and soft tissue discharge $48(31.6 \%)$, blood $9(5.9 \%)$ and ascitic fluid $6(3.9 \%)$ [Table-1]. Majority of them 116 $(76.3 \%)$ were detected from in-patients i.e, intensive care units 49 (32.3\%), surgical wards 37 (24.3) and medicine wards (19.7\%) [Table-2]. The mean age of Enterococcus isolated study participants was $55.8 \pm 13.6$ years.

\section{Antimicrobial resistance pattern:}

From 152 enterococcal isolates, 20 (13.2\%) were detected as VRE in VRE agar based screening method. In KBDDM, out of 20 VRE isolates, 12 were VR E. faecalis and 8 were VR E. faecium. The distribution of antimicrobial 
susceptibility patterns of isolated enterococci were summarized in Table (3). The results showed that majority of isolates were resistant to penicillin $(67.1 \%)$, followed by ampicillin (61.2\%), ciprofloxacin (58.5\%), high-level gentamicin (46.7\%), high-level streptomycin (42.8\%), vancomycin (13.2\%), teicoplanin (7.9\%). All enterococcal isolates were sensitive to linezolid. Out of 20 VRE, 8 (40\%) were resistant, 9 (45\%) were intermediately resistant and $3(15 \%)$ were sensitive in E-test. The distribution pattern of teicoplanin E-test for VRE isolates were 6 (30\%) resistant, $6(30 \%)$ were intermediately resistant and $8(40 \%)$ were sensitive [Table-4]. All VRE isolates had MIC values of $\leq 2 \mu \mathrm{g} / \mathrm{ml}$ and were interpreted as linezolid sensitive.

Detection of vancomycin phenotypes and genotypes:

From 20 VRE isolates, 6 had high-level vancomycin resistance (MIC $\geq 64 \mu \mathrm{g} / \mathrm{ml}$ ) and high-level teicoplanin resistant (MIC $\geq 16 \mu \mathrm{g} / \mathrm{ml}$ ) were detected as VanA phenotype and 2 had highlevel vancomycin resistance (MIC $\geq 32 \mu \mathrm{g} / \mathrm{ml}$ ) and teicoplanin sensitive (MIC $\leq 0.25 \mu \mathrm{g} / \mathrm{ml}$ ) were detected as VanB phenotype. All VanA phenotype isolates were positive for vanA gene cluster [Figure 2].

Table (1): Distribution of Enterococcus Species in various clinical specimens

\begin{tabular}{|l|c|c|c|c|}
\hline \multirow{2}{*}{ Type of clinical specimen } & \multicolumn{2}{|c|}{ Number (\%) of Enterococcal species isolated } & \multirow{2}{*}{ Total (\%) } \\
\cline { 2 - 4 } & $\boldsymbol{E}$. faecalis & E. faecium & E. casseliflavus & \\
\hline Urine & 58 & 31 & 0 & $89(58.6)$ \\
\hline $\begin{array}{l}\text { Skin and soft tissue } \\
\text { discharge }\end{array}$ & 29 & 18 & 1 & $48(31.6)$ \\
\hline Blood & 6 & 3 & 0 & $9(5.9)$ \\
\hline Ascitic Fluid & 4 & 2 & 0 & $6(3.9)$ \\
\hline Total (\%) & $97(63.8)$ & $54(35.5)$ & $1(0.7)$ & $152(100)$ \\
\hline
\end{tabular}

Table (2): Distribution of Enterococcus in various clinical units

\begin{tabular}{|c|c|c|c|c|}
\hline \multirow{2}{*}{$\begin{array}{c}\text { Type of clinical } \\
\text { units }\end{array}$} & \multicolumn{3}{|c|}{ Number $(\%)$ of Enterococcal species isolated $(n=152)$} & \multirow{2}{*}{ Total $(\%)$} \\
\hline & E.faecalis & E. faecium & E. casseliflavus & \\
\hline Out-patient units & 23 & 13 & & $36(23.7)$ \\
\hline \multicolumn{5}{|l|}{ In-patient units } \\
\hline $\begin{array}{l}\text { ICUs } \\
\text { Surgical units }\end{array}$ & $\begin{array}{l}32 \\
22\end{array}$ & $\begin{array}{l}17 \\
14\end{array}$ & 1 & $37(24.3)$ \\
\hline Medicine units & 20 & 10 & & $30(19.7)$ \\
\hline Total (\%) & $97(63.8)$ & $54(35.5)$ & $1(0.7)$ & $152(100)$ \\
\hline
\end{tabular}

Table (3): Antimicrobial resistance pattern of enterococcal isolates

\begin{tabular}{|l|c|c|c|}
\hline \multirow{2}{*}{\multicolumn{1}{|c|}{ Antibiotic (disk content) }} & \multicolumn{3}{|c|}{ Resistance } \\
\cline { 2 - 4 } & $\begin{array}{c}\text { E. faecalis } \\
\mathbf{n = 9 7}(\mathbf{\%})\end{array}$ & $\begin{array}{c}\boldsymbol{E} \text {. } \text { faecium } \\
\mathbf{n = 5 4}(\boldsymbol{\%})\end{array}$ & $\begin{array}{c}\text { Total* } \\
\mathbf{n = 1 5 2}(\boldsymbol{\%})\end{array}$ \\
\hline Penicillin $(10 \mathrm{Units})$ & $63(64.9)$ & $39(72.2)$ & $102(67.1)$ \\
\hline Ampicillin $(10 \mu \mathrm{g})$ & $58(59.8)$ & $35(64.8)$ & $93(61.2)$ \\
\hline Ciprofloxacin $(5 \mu \mathrm{g})$ & $54(55.7)$ & $35(64.8)$ & $89(58.6)$ \\
\hline High-level gentamicin $(120 \mu \mathrm{g})$ & $46(47.4)$ & $25(46.3)$ & $71(46.7)$ \\
\hline High-level streptomycin $(300 \mu \mathrm{g})$ & $42(43.3)$ & $23(42.6)$ & $65(42.8)$ \\
\hline Vancomycin $(30 \mu \mathrm{g})$ & $12(12.4)$ & $08(14.8)$ & $20(13.2)$ \\
\hline Teicoplanin $(30 \mu \mathrm{g})$ & $06(6.2)$ & $06(11.1)$ & $12(7.9)$ \\
\hline Linezolid $(30 \mu \mathrm{g})$ & 0 & 0 & 0 \\
\hline
\end{tabular}

*One $E$. casseliflavus isolate was sensitive to vancomycin, teicoplanin and linezolid 
Table (4): Distribution of vancomycin resistant enterococci according to its phenotypic and genotypic characteristics

\begin{tabular}{|c|c|c|c|c|c|c|c|c|}
\hline \multirow{2}{*}{$\begin{array}{c}\text { Isolate } \\
\text { number } \\
\text { E. faecalis }\end{array}$} & \multicolumn{3}{|c|}{$\begin{array}{l}\text { MIC values of vancomycin } \\
\qquad(\mu \mathrm{g} / \mathrm{ml})\end{array}$} & \multicolumn{3}{|c|}{$\begin{array}{l}\text { MIC values of teicoplanin } \\
\qquad(\mu \mathrm{g} / \mathrm{ml})\end{array}$} & \multirow[t]{2}{*}{$\begin{array}{c}\text { Phenotype of } \\
\text { vancomycin } \\
\text { resistance } \\
\end{array}$} & \multirow[t]{2}{*}{$\begin{array}{c}\text { Genotype of } \\
\text { vancomycin } \\
\text { resistance }\end{array}$} \\
\hline & $\begin{array}{c}\leq 4 \\
S^{*}\end{array}$ & 8-16 $I^{* *}$ & $\geq 32 \mathbf{R}^{* * * *}$ & $\leq 2 \quad \mathrm{~S}^{*}$ & $4 \quad I^{* *}$ & $\geq 8 \quad R^{* * * *}$ & & \\
\hline 1 & 2 & & & 1.5 & & & & \\
\hline 2 & & & 32 & 0.25 & & & VanB & \\
\hline 3 & & & 96 & & & 32 & VanA & vanA \\
\hline 4 & & 8 & & & 4 & & & \\
\hline 5 & & 8 & & 2 & & & & \\
\hline 6 & & & 256 & & & 96 & $\operatorname{Van} A$ & vanA \\
\hline 7 & & & 64 & & & 64 & VanA & vanA \\
\hline 8 & & 16 & & & 4 & & & \\
\hline 9 & & 8 & & 2 & & & & \\
\hline 10 & 4 & & & 0.5 & & & & \\
\hline 11 & & & 32 & 0.125 & & & VanB & \\
\hline 12 & & 16 & & 2 & & & & \\
\hline \multicolumn{9}{|l|}{$\begin{array}{l}\text { Isolate } \\
\text { number } \\
\text { E. faecium }\end{array}$} \\
\hline 1 & & 8 & & & 4 & & & \\
\hline 2 & 4 & & & 0.75 & & & & \\
\hline 3 & & & 256 & & & 16 & VanA & vanA \\
\hline 4 & & & 128 & & & 32 & $\operatorname{Van} A$ & vanA \\
\hline 5 & & 16 & & & 4 & & & \\
\hline 6 & & 8 & & & 4 & & & \\
\hline 7 & & & 96 & & & 32 & VanA & vanA \\
\hline 8 & & 8 & & & 4 & & & \\
\hline
\end{tabular}

${ }^{*}$ S- Sensitive, I I** - Intermediately resistant, $\mathrm{R}^{* * * *}$ - Resistant 


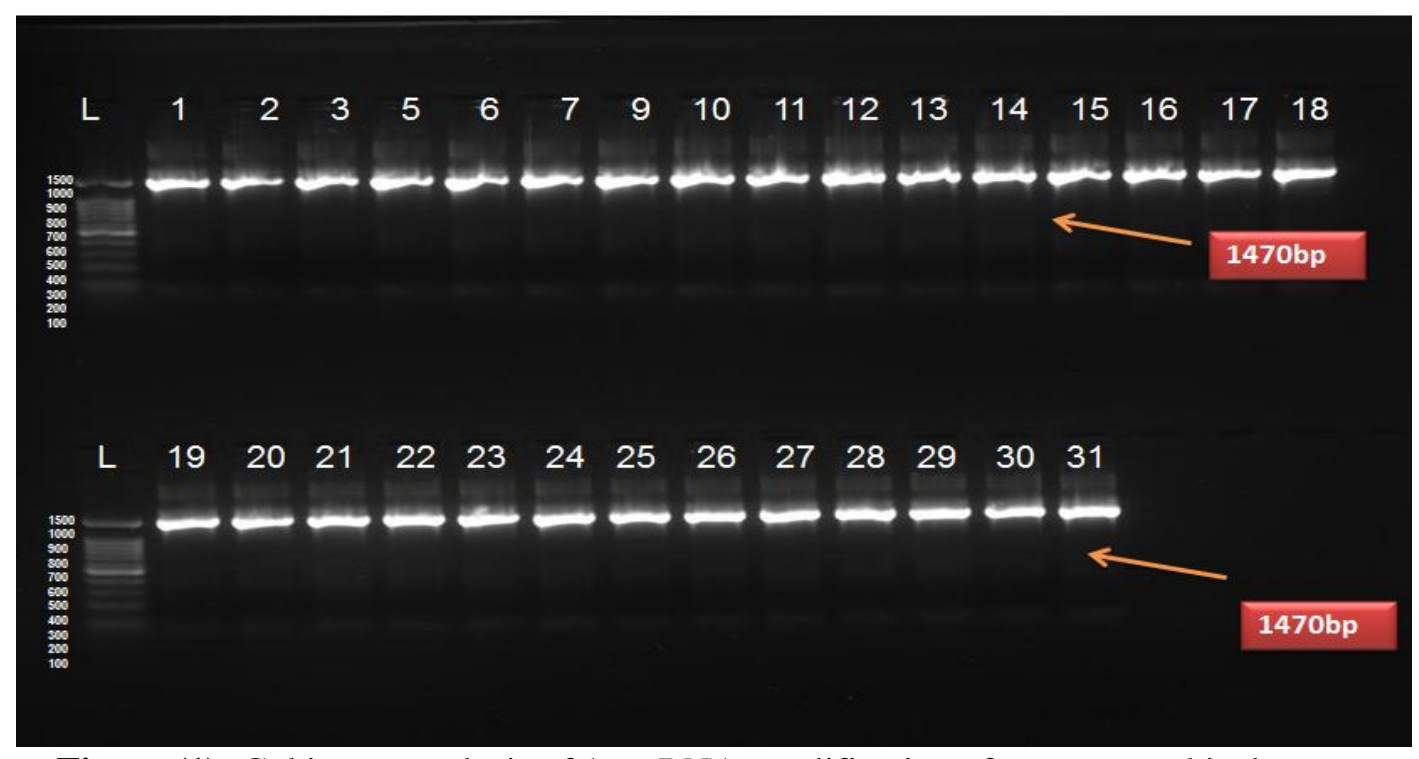

Figure (1): Gel image analysis of 16s rRNA amplification of enterococcal isolates L: Marker (100 to $1500 \mathrm{bp}$, DNA ladder) 1 to 31: Enterococcus species (1470 bp)

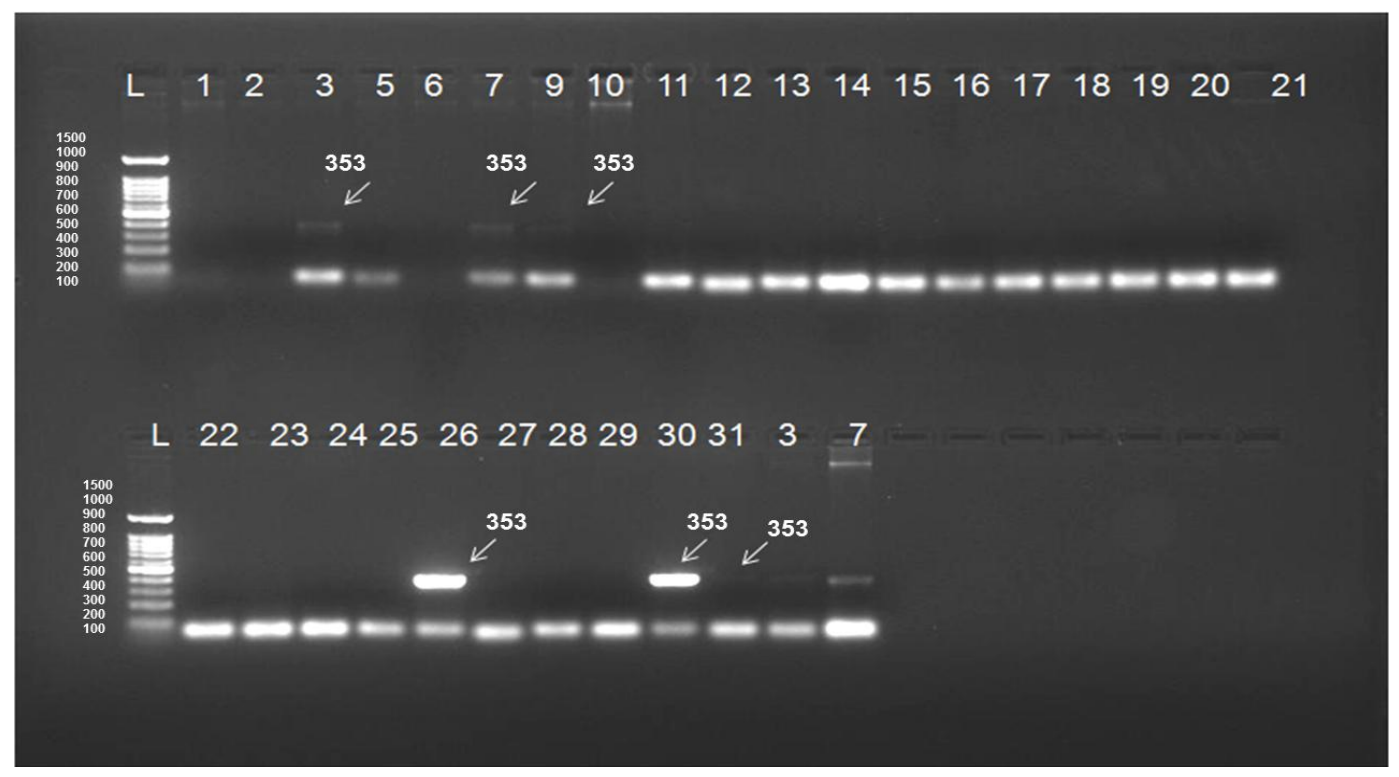

Figure (2): Agarose gel electrophoresis showing positive amplification of 353 base pair fragments specific for vanA from VRE isolates. Lane 1: Marker (100 to $1500 \mathrm{bp}$, DNA ladder), Lane 3, 7 \& 9: E. faecalis vanA gene cluster, Lane 26, 30 \& 31: E. faecium vanA gene cluster, Lane 3: Negative control (without template DNA), Lane 7: Positive control (E. faecium 15559 containing vanA gene cluster) 


\section{DISCUSSION}

Enterococcus is a part of normal human intestinal flora and traditionally regarded as low grade pathogen. During last two decades, it has emerged as increasingly important nosocomial infections. Vancomycin in combination with an aminoglycoside can provide effective treatment for severe Enterococcus infections, while increasingly resistant to both antibiotics have been reported in different parts of the world $[12,13,14]$. In this study the pattern of antibiotics resistance, prevalence of VRE and most commonly associated vanA gene cluster were explored. Present study was conducted at a tertiary care hospital, Odisha state, Eastern India consisted of 152 non-repeated strains of Enterococcus species that were isolated from hospitalized and outpatients.

In our study from 961 culture positive growth, $152(15.8 \%)$ Enterococcus species were isolated. The most common species isolated was $E$. faecalis $(63.8 \%)$ followed by E. faecium (35.5\%) and $E$. casseliflavus $(0.7 \%)$ which was comparable to the distribution of Enterococcus species in different parts of the world [15-22]. Predominance of $E$. faecalis in the endogenous flora of the body could be the reason behind its high proportion among hospital isolates. While E. faecalis remains the predominant species in clinical infections, E. faecium isolates are increasing in proportion.

Present study revealed the most frequent infection was urinary tract infections $(58.6 \%)$, followed by skin and soft tissue infections (31.6\%) and blood stream infections (BSIs). Similar distribution of Enterococcal infections were reported in previous studies $[\mathbf{2 2 , 2 4 , 2 5 ]}$. In these settings, enterococci are part of endogenous mixed flora commonly found in the gastrointestinal tract [26]. Majority of Enterococcal infections were detected from hospitalized patients and more commonly seen among patients in intensive care units (ICUs) and surgical wards. Similar incidence rate were found by other authors [25]. Prolonged ICU hospital stay and increased invasive procedure applications are some possible explanations.

Resistance to B-lactam antibiotics i.e., penicillin and ampicillin were observed in $67.1 \%$ and $61.2 \%$ respectively in our study. Similar B-lactam resistant rates were detected in other studies $[\mathbf{1 8 , 2 1 , 2 2 , 2 7 ]}$. Recently, a study conducted by Bhatt et. al. had shown $97.5 \%$ of all enterococcal isolates were resistant to both penicillin and ampicillin [28]. Since B-lactams remain the drug of choice for most non-severe enterococcal infections, increasing resistance to these antibiotics is of global concern. High-level B-lactam resistance in enterococci is due to the production of low affinity penicillin binding proteins 5 (PBP 5 ), or the production of ß-lactamases [29]. Our study revealed HLG and HLS resistance were $46.7 \%$ and $42.8 \%$ of all isolates respectively. Similar resistance rates were detected in other studies $[19,20,27,28,30,31]$. However, in a study performed by Deshpande et al. [18] had revealed a high proportion of test isolates exhibited resistance to HLG (73.5\%) and HLS (70.8\%) respectively. High-level resistance to aminoglycosides is acquired through two mechanisms: modification of ribosomal attachment sites and the production of aminoglycoside-modifying enzymes [32]. The presence of high level resistance to aminoglycosides destroys the bactericidal activity obtained with B-lactam and aminoglycoside synergy in clinical practice [33].

In our study from 152 enterococcal isolates, 20 (13.2\%) VRE were obtained by VRE agar screen test and KBDDM. Similarly percentage of VRE isolates were obtained from other studies [17, $\mathbf{2 0 , 2 1 , 2 2 , 2 4 , 2 8 ]}$. Higher vancomycin resistance rates of $21.05 \%$ and $19.6 \%$ were reported by Oberoi et. al. and Deshpande et al. respectively $[\mathbf{1 9 , 1 8}]$. Some researchers even did not find a single isolate of VRE from their studies $[\mathbf{2 5}, \mathbf{3 0}]$. The prevalence of VRE is reported to be between $0 \%$ to $30 \%$ in various studies across the world $[\mathbf{1 6 , 1 7 , 1 9 , 2 4 , 2 5 ]}$. Glycopeptides such as vancomycin and teicoplanin are cell-wall active agents, exerting their antimicrobial effect by binding with high affinity to D-Ala-D-Ala termini of pentapeptide precursors in order to inhibit the synthesis of peptidoglycans. Glycopeptide resistance arises when low-affinity pentapeptide precursors D-Ala-D-Lac or D-Ala-D-Ser are formed and high affinity precursors D-Ala-D-Ala are eliminated [34]. Among VRE isolates, $40 \%$ were resistant with high MIC values (64 to $256 \mu \mathrm{g} / \mathrm{ml}$ ), $45 \%$ were intermediately resistant and $15 \%$ isolates were sensitive in E-test. Similarly, Sreeja et al. [31] had reported $27 \%$ of the enterococci which showed intermediate resistant to vancomycin by KBDDM, were found to be sensitive to vancomycin in E-test. The inaccuracy of disc diffusion and screening method has resulted in inappropriate use of this drug as a part of treatment regimen. Our study revealed $12.4 \%$ 
were VR E. faecalis and $14.8 \%$ were VR E. faecium. Similar resistance pattern was observed by Deshpande et. al. [18] in contradiction to these studies, Vidyalakshmi et. al. [35] reported, out of 450 enterococcal isolates, $18(4 \%)$ were VRE and all isolates belonged to E. faecium. In the early 1990s, E. faecalis resistance was low against vancomycin and ampicillin while $E$. faecium were high $(60 \%$ and $80 \%$ respectively) and are raising trend [36]. In recent times, the species difference is very unusual, because the gene responsible for this resistance can be transferred easily in the laboratory between the two species carried on pheromone responsive plasmids or conjugative transposons [23]. In our study, from 152 enterococcal isolates 12 (7.9\%) were resistant to teicoplanin in KBDDM. Out of 20 VRE isolates, 6 were resistant (MIC $\geq 8$ $\mu \mathrm{g} / \mathrm{ml}), 6$ were intermediately resistant $(4 \mu \mathrm{g}) / \mathrm{ml}$ and 8 isolates were sensitive in E-test. Similar resistance pattern of enterococci towards teicoplanin were observed by various authors [18,24,28] Fernandes et. al. [20] were noticed that from thirteen VRE isolates, five were resistant to teicoplanin. Based on MIC values of vancomycin and teicoplanin, majority of isolates $6(30 \%)$ in our study were VanA phenotype (three $E$. faecalis and 3 E. faecium) and $2(10 \%)$ were VanB phenotype (E. faecalis).

In our study all enterococcal isolates were sensitive to linezolid in KBDDM. MIC values of all VRE isolates were $\leq 2 \mu \mathrm{g} / \mathrm{ml}$. Other studies have also reported $100 \%$ enterococcal isolates were sensitive to linezolid $[\mathbf{2 2 , 2 4 , 2 5 , 3 0 , 3 1 ] . ~ F e w ~}$ studies had also detected linezolid resistance cases $[\mathbf{1 7 , 1 8 , 2 8}]$. Linezolid resistance is rare in enterococci. Variety of sporadic point mutations in rRNA genes that confer linezolid resistance have been identified, the most common of which is G2576T [37].

Genotypic detection for the vanA gene using conventional PCR revealed that $6(30 \%)$ VRE isolates were positive for this gene yielding a band size of $390 \mathrm{bp}$. These isolates also showed a high level resistance to vancomycin and teicoplanin (VanA phenotype). The vanA gene was present in three isolates each of $E$. faecalis and $E$. faecium. Recently, Zadeh et al. [24] in Iran had reported 59\% of vancomycin-resistant strains carried vanA gene and $7.95 \%$ of VRE strains carried $v a n B$ gene. Similarly, Yasliani et al. [17] had studied 17 VRE for their van genotypes by PCR found $6(35.2 \%),, 4(23.5 \%)$ and $1(5.88 \%)$ of vanA, vanB and vanC gene respectively. In another study by Salem-Bekhit et al. [16] in Saudi Arabia detected all seven VanA phenotypes were positive for vanA gene and a 732-bp PCR product was obtained in all positive isolates. One intermediate vancomycin resistant isolate was detected as $v a n B$ genotype (635-bp). VanA phenotype associated with vanA gene cluster found on the transposon, or "jumping" genetic element, Tn 1546 is responsible for most of the human cases of VRE around the world, and is mostly carried by E. faecium [38].

There were few limitations in our study. The Etest for detection of MIC values could be performed only in VRE isolates using vancomycin, teicoplanin and linezolid antibiotic strips. The most common vanA gene cluster could be detected in conventional PCR. The availability and the cost factor were major hindrance for this study.

\section{CONCLUSION}

The prevalence of VRE in vancomycin screen agar and KBDDM was $13.2 \%$. Enterococci were most commonly isolated from ICUs and surgical wards and UTI was the most commonly associated infection. VanA and VanB phenotype were obtained in $40 \%$ of VRE isolates and $30 \%$ of isolates were associated with vanA gene. More reliable MIC determination test may be performed in all suspected VRE isolates, so that vancomycin resistance phenotypes can be detected and appropriate therapy may be initiated. When-ever feasible PCR should be used for confirmation of VRE genotypes. Thus, a cooperative effort between health care providers and hospital microbiology laboratory personnel is required that will allow VRE to be promptly and accurately detected. Surveillance cultures in high prevalence areas such as ICUs and surgical wards are immediate requirements in order to keep the spread of vancomycin resistance in control.

\section{Acknowledgment}

We sincerely acknowledge Kalinga Institute of Industrial technology-technology business incubator (KIIT-TBI) conducting PCR amplification for vanA gene.

\section{Funding:Non. \\ Conflicts of interest: None. Ethical approval:Approved.}




\section{REFERENCES}

1. Murray BE, Weinstock GM. Enterococci: new aspects of an old organism. Proc Assoc Am Physicians 1999; 111:328-34.

2. Gordon S, Swenson JM, Hill BC, Pigott NE, Facklam RR, Cooksey RC, et al. Antimicrobial susceptibility pattern of common and unusual species of Enterococci causing infection in the United States. Enterococcal Study Group. J Clin Microbiol 1992;30:2373-8.

3. Low DE, Keller N, Barth A, Jones RN. Clinical prevalence, antimicrobial susceptibility, and geographic resistance patterns of enterococci: results from the SENTRY Antimicrobial Surveillance Program, 1997-1999. Clin Infect Dis 2001; 32:S133-45.

4. Schaberg DR, Culver DH, Gaynes RP. Major trends in the microbial etiology of nosocomial infection. Am J Med 1991;91:72S-75S.

5. Murray BE. Diversity among multi-drug resistant enterococci. Emerg Infect Dis 1998;4:37-47.

6. Huyke MM, Sham DF, Glimore MM. Multiple drug resistance enterococci: The nature of the problem and the agenda for the future. Emerg Infect Dis 1998; 4:239-49.

7. www.cdc.gov [Internet]. CDC/NHSN Surveillance Definition of Healthcare-Associated Infection and Criteria for Specific Types of Infections in the Acute Care Setting; c2013. Available from: http://www.cdc.gov/nhsn/pdfs/pscmanual/17pscn osinfdef_current.pdf [Last updated on 2013 April; cited on 2015 Sept 28].

8. Colle JG, Marmion BP, Fraser AG, Simmons A. Mackie and McCartney practical Medical Microbiology. 14 ${ }^{\text {th }}$ ed. New Delhi; Elsevier; 2006. p.266-72.

9. Facklam RR, Teixeira LM. Enterococcus. In: Lollier, BalowsA, Sussman M. editors. Topley and Wilson's microbiology and microbial infection. $9^{\text {th }}$ ed. New York; Oxford University Press; 1998.p.669-82.

10. Bauer AW, Kirby WM, Sherris JC, Turck M. Antibiotic susceptibility testing by a standardized disc diffusion method. Am J Clin Pathol 1966; 45: 493-6.

11. Clinical and Laboratory Standards Institute, Performance standards for antimicrobial susceptibility testing; Twentieth Informational Supplement, vol. 30, M100-S20. Wayne, Pa, USA: CLSI; 2010.

12. Bonten MJ, Willems R, Weinstein RA. Vancomycin -resistant enterococci: why are they here, and where do they come from? .Lancet Infect Dis 2001; 1:314-25.
13. Frieden TR, Munsiff SS, Low DE, Willey BM, Williams G, Faur Y, et al. Emergence of vancomycin-resistant enterococci in New York City. Lancet 1993 ; 342:76-9.

14. The European Antimicrobial Resistance Surveillance System. EARS-Net Results; 2015; Available from: http://www.ecdc.europa.eu/en/ healthtopics/antimicrobial_resistance/database/Pa ges/database.aspx. Accessed January 1, 2015

15. Hashem YA, Yassin AS, Amin MA. Molecular characterization of Enterococcus spp. clinical isolates from Cairo, Egypt. Indian $J$ Med Microbiol 2015; 33:S80-86.

16. Salem-Bekhit MM, Moussa IMI, Muharram MM, Alanazy FK, Hefni HM. Prevalence and microbial resistance pattern of multi-drug resistant enterococci isolated from clinical specimens. Indian J Med Microbiol 2012;30:44-51.

17. Yasliani S, Mohabati Mobarez A, Hosseini Doust R, Satari M, Teymornejad O. Linezolid vancomycin resistant Enterococcus isolated from clinical samples in Tehran hospitals. Indian J Med Sci 2009; 63:297-302.

18. Deshpande VR, Karmakar MG, Mehta PR. Prevalence of multidrug-resistant enterococci in a tertiary care hospital in Mumbai, India. $J$ Infect Dev Ctries 2013; 7:155-8.

19. Oberoi L, Aggarwal A. Multidrug resistant Enterococci in a rural tertiary care hospital- A cause of concern. JK Science 2010; 12:157-8.

20. Fernandes SC, Dhanashree B. Drug resistance and virulence determinants in clinical isolates of Enterococcus species. Indian J Med Res 2013; 137:981-5.

21. Gangurde N, Mane M, Phatale S. Prevalence of multidrug-resistant enterococci in a tertiary care hospital in India: A growing threat. Open J Med Microbiol;4:11-5.

22. Shah L, Mulla S, Patel KG, Rewadiwala S. Prevalence of enterococci with higher resistance level in a tertiary care hospital: A matter of concern. Natl Med J Res 2012;2:25-7.

23. Sood S, Malhotra M, Das BK, Kapil A. Enterococcal infections \& antimicrobial resistance. Indian J Med Res 2008;128:111-21.

24. Zadeh AH, Shojapour M, Nazari R, Akbari M, Sofian M, Abtahi H. Genotyping of vancomycin resistance enterococci in arak hospitals. Jundishapur J Microbiol 2015; 8:e16287.

25. Shinde RS, Koppikar GV, Oommen S. Characterization and antimicrobial susceptibility pattern of clinical isolates of Enterococci at a tertiary care hospital in Mumbai, India. Ann Trop Med Public Health 2012; 5:85-8. 
26. Moellering RC Jr. Enterococcus species, Streptococcus bovis and Leuconostoc species. In: Mandell GL, Bennett JE, Dolin R, editors. Mandell, Douglas and Bennett's principle and practice of infectious diseases. $5^{\text {th }}$ ed. Vol. 2 . New York: Churchill Livingstone; 2000. p. $2147-$ 56.

27. Rahangdale VA, Agrawal G, Jalgaonkar SV. Study of antimicrobial resistance in enterococci. Indian J Med Microbiol 2008;26:286-7.

28. Bhatt P, Patel A, Sahni AK, Praharaj AK, Grover $\mathrm{N}$, Chaudhari $\mathrm{CN}$, et al. Emergence of multigrug resistant enterococci at a tertiary care centre. Med J Armed Forces India 2015;71:139-44.

29. Arias CA, Contreras GA, Murry BE. Management of multidrug-resistant enterococcal infections. Clin Microbiol Infect 2010;16:555-62.

30. Chakraborty A, Pal NK, Sarkar S, Gupta MS. Antibiotic resistance of Enterococci isolates from nosocomial infections in a tertiary care hospital in Eastern India. J Nat Sc Biol Med 2015;6:394-7.

31. Sreeja S, Sreenivasa Babu PR, Prathab AG. The prevalence and the characterization of the Enterococcus species from various clinical samples in a tertiary care hospital. J Clin Diagn Res 2012; 6:1486-8.

32. Moellering RC Jr, Weinberg AN. Studies on antibiotic synergism against enterococci.II. Effect of various on the uptake of 14 C-labeled streptomycin by enterococci. J Clin Invest 1971; 50:2580-4.
33. Eliopoulos GM. Aminoglycoside resistant enterococcal endocarditis. Infect Dis Clin North Am 1993; 7:117-33.

34. Walsh C. Molecular mechanisms that confer antibacterial drug resistance. Nature 2000; 406: 775-81.

35. Vidyalakshmi PR, Gopalakrishnan R, Ramasubramanian V, Gafur KA, Nambi PS. Thirunarayana MA. Clinical, epidemiological, and microbiological profile of patients with vancomycin-resistant Enterococci from a tertiary care hospital. J Global Infect Dis 2012;4:137-8.

36. Edwards DD. Enterococci attract attention to concerned microbiologists. ASM News 2000; 66: 540-5.

37. Farrell DJ, Mendes RE, Ross JE, Sader HS, Jones RN. LEADER Program results for 2009: an activity and spectrum analysis of linezolid using 6,414 clinical isolates from 56 medical centers in the United States. Antimicrob Agents Chemother 2011;55:3684-90.

38. Arthur M, Courvalin P. Genetics and mechanisms of glycopeptide resistance in enterococci. Antimicrob Agents Chemother 1993; 37:1563-71.

Peer reviewer: Eman A. El Masry, Department of Medical Microbiology and Immunology, Faculty of Medicine, Menoufia, Egypt

Editor: Mohamed H Emara; Lecturer of Tropical Medicine, Faculty of Medicine, Zagazig University, Egypt. 